\title{
ベクトルウェーブレット変換による乱流構造の可視化
}

李 輝 $^{\circ}$ (鹿児島大学), Yu ZHOU (香港理工大学), 武居 昌宏 (日本大学) 斉藤 兆古 (法政大学), 堀井 清之 (白百合女子大学)

\section{Visualization of Turbulent Structure Using Vector Wavelet Transform}

\author{
Hui LI, Yu ZHOU, Masahiro TAKEI, Yoshifuru SAITO and Kiyoshi HORII
}

\begin{abstract}
A vector multiresolution decomposition technique based on a two-dimensional orthogonal wavelet transform was proposed in this paper. This technique was used to analyze the velocity data obtained in the turbulent near-wake of a circular cylinder. The data were simultaneously sampled using sixteen X-wires. The investigation aims to visualize turbulence structures of various scales. The instantaneous velocity vector and vorticity fields were decomposed into various scale structures. The large-scale structures with a central frequency of $108 \mathrm{~Hz}$ in the plane of mean shear are consistent with the well-known Karman vortices. The rib-like structures that correspond to the saddle region between Karman vortices were visualized.
\end{abstract}

Keywords: Eddy, Turbulence, Vector wavelet transform, Visualization, Wake

\section{1. 緒 論}

円柱後流に形成される渦の可視化は、渦の基本構造と 特性を不可欠に必要とする航空学上の重要課題として広 く研究されてきた。特に、流体抵抗や流体関連振動の低 減のために、後流流れ場に対して高度な知的制御を目指 した先端的研究が注目されている。後流乱流を制御して 新しい技術を創成するため、基本となる渦構造の詳細解 明は不可欠な条件である。

レイノルズ数が高いとき、円柱などの二次元物体の下 流には、物体からの周期的に渦放出によりカルマン渦列 が形成されることがよく知られている(1)。カルマン渦列 は下流では三次元的に複雑な構造をもち、大小様々な渦 からなる。残念ながら、今までの変動速度のスペクトル 解析は周波数を最大限取り出すために時間軸情報が全く 犠牲にされているため、いまだその構造は十分に明らか ではないといえる。しかし、この様々なスケール渦の非 定常挙動、すなわち、時間一空間一周波数空間における 定量的に渦の可視化には、後流乱流の制御に対するたい

\begin{abstract}
ヘん重要である。
ウェーブレットは過去十年ほどの間に急速に進歩した 分野である。従来から用いられたフーリエ解析を超える 新しい非定常現象の処理方法として注目されている。流 体工学の分野では、国内外におけるウェーブレット解析 は乱流の研究に応用されてきた (2), (3)。この方法の最大 の特徴は、信号中の様々なスケールの分布を、元の時間 軸情報を失わずに抽出することができる点にある。

円柱後流の多重スケール渦の構造を抽出するため、本 研究は、ベクトルウェーブレット多重解像度法を用いて 高時間分解能の実験データを解析する。時間一空間一周 波数空間における流線と渦度の表示によって後流乱流の 渦構造を定量的に可視化する。
\end{abstract}

\section{2. 実験の方法}

実験は、測定部の断面 $350 X 350 \mathrm{~mm}$ 、長さ $2400 \mathrm{~mm}$ の開放形回流風洞に十分滑らかな表面をもつ供試円柱 （直径 $d=12.5 \mathrm{~mm}$ ) を取り付け、主流速度 $U_{\mathrm{s}}=6.7 \mathrm{~m} / \mathrm{s}$ 、 
レイノルズ数 $R e=5600$ において行った。計測システム は、図 1 に示すように、主流方向位置 $x / d=20$ における $\mathrm{X}$ 型熱線プローブ 16 本を用いて変動速度を同時に測定 した。円柱の渦放出周波数は、約 $109 \mathrm{~Hz}$ となるため、 $3.5 \mathrm{kHz}$ の周波数で速度変動波形のサンプリングを行っ た。

\section{3. ベクトルウェーブレット多重解像度法}

時系列二次元ベクトル信号 $\vec{f}\left(x_{1}, x_{2}\right) （ \mathrm{x}_{1}$ : 時間、 $\mathbf{x}_{2}$ :

空間位置、 $\vec{f}$ : 速度ベクトル $(u, v))$ と二次元直交ウ エーブレット基底関数

$$
\Psi_{m_{1}, n_{1} ; m_{2}, n_{2}}\left(x_{1}, x_{2}\right)=2^{-\left(m_{1}+m_{2}\right) / 2} \psi\left(2^{-m_{1}} x_{1}-n_{1}\right) \psi\left(2^{-m_{2}} x_{2}-n_{2}\right)
$$

に対して二次元ベクトルウェーブレット変換は次の式で 定義される。

$$
\overrightarrow{W f}_{m_{1}, m_{1} ; m_{2}, n_{2}}=\sum_{i} \sum_{j} \vec{f}\left(x_{1}^{i}, x_{2}^{j}\right) \Psi_{m_{1}, n_{1} ; m_{2}, n_{2}}\left(x_{1}^{i}, x_{2}^{j}\right) .
$$

$\overrightarrow{W f}_{m 1, n 1 ; m 2, n 2}$ はベクトルウェーブレット係数、 $\psi(x)$ は一 次元直交ウェーブレット基底関数である。本研究ではド ビッシーの 20 次基底関数を使用した。二次元ベクトル ウェーブレット逆変換は

$$
\vec{f}\left(x_{1}^{i}, x_{2}^{j}\right)=\sum_{m_{1}} \sum_{m_{2}} \sum_{m_{1}} \sum_{m_{2}} \overrightarrow{W f}_{m_{1}, m_{1} ; m_{2}, m_{2}} \Psi_{m_{1}, m_{1} ; m_{2}, m_{2}}\left(x_{1}^{i}, x_{2}^{j}\right)
$$

で定義される。

本研究では、時系列二次元ベクトル信号を周波数空間 で分解するために、次のベクトルウェーブレット多重解 像度法を提案した。

(a) 時系列二次元速度ベクトル $\vec{f}\left(x_{1}, x_{2}\right)$ をベクトルウェ ーブレット変換して、各レベルのベクトルウェーブレッ 卜係数が得られる。

(b) ベクトルウェーブレット係数をレベルごとに逆変換 して、もとの速度ベクトルは低周波成分から高周波成分 に分解される。

\section{4. 結果と考察}

本研究では $(\mathrm{x}, \mathrm{y})$ 平面における渦構造を着目する。 $(\mathrm{x}, \mathrm{y})$ 平面内の 8 本の $\mathrm{X}$ 型プローブで同時に計測 した二次元速度ベクトル $(u, v)$ から大規模渦の平均
対流速度とみなせる $U_{c}=0.87 U$ ，を差引いた速度を用いて 流線図を描かせた。この平面における渦度分布は次の式

$$
\omega_{z i}=\frac{\Delta v_{i}}{\Delta x}-\frac{\Delta\left(\bar{U}+u_{i}\right)}{\Delta y}
$$

で計算する。ここで、 $u_{i}, v_{i}$ は変動速度成分、 $\bar{U}$ は $\mathrm{x}$ 方向の時間平均速度である。プローブ間隔は $\Delta y=5.0 \mathrm{~mm}$ となり、 $\mathrm{x}$ 方向の間隔は Taylor の凍結乱流 の仮説により $\Delta x=-U_{c} \Delta t$ で計算する。図 2 に実験の生デ 一タの流線と渦度分布を示す。縦方向の座標は $y / d$ 、横 方向の座標は $U_{c} t / d$ およびカラーの変化は速度 (黄、赤) と渦度（黒、緑）の大きさを示している。渦度は渦の強 さと回転の方向を表しており、黒 (緑) 色が時計（反時 計）回りに回転している渦である。罒 2 から変形された カルマン渦列（大規模渦）が現出し、様々なスケール渦 が存在することがわかった。しかし、この図から渦のス ケールの評価と各スケールの渦構造の抽出は困難である。

この問題を解決するため、本研究では、ベクトル多重 解像度法によって変動速度ベクトルを周波数空間に分解 した。図 3 は中心周波数 $109 \mathrm{~Hz} 、 219 \mathrm{~Hz} 、 438 \mathrm{~Hz} 、 875 \mathrm{~Hz}$ および $1750 \mathrm{~Hz}$ における流線と渦度分布を示したもので ある。FFT スペクトル解析の結果によってカルマン渦列 の平均周波数は約 $109 \mathrm{~Hz}$ である。図 3 (a)から、中心周 波数 $109 \mathrm{~Hz}$ における周期的なカルマン渦列（大規模渦） が図 2 から分解され、明瞭に観察される。二つ大渦の間 にある鞍部点も鮮明に見える。これらの渦の位置は之れ ぞれ図 2 中の大渦に対応している。中心周波数は $219 \mathrm{~Hz}$ まで増加すると、図 3 (b)に示寸ように、周期性をもつ 中スケールの渦列が現れる。図 3 (a)に比較すると、こ れらの中スケールの渦はカルマン渦（大規模渦）中また は鞍部点の位置に存在していることがわかる。図 3 (c) は中心周波数 $438 \mathrm{~Hz}$ の渦分布を示す。これらの渦のス ケールは図 $3(\mathrm{~b})$ より 小さく、渦列の規則性は強くなっ ている。さらに、図 3 (c) の渦列は大規模渦（図 3 (a)) と中スケールの渦（図 $3(\mathrm{~b})$ ) 中に含まれることがわか る。図 3 (c) と図 2 を比較すると、一部の中心周波数 $438 \mathrm{~Hz}$ の渦は図 2 中の小渦に対灾している。このこと から実験の生データの流線と渦度分布（図2）は中心周 波数 $438 \mathrm{~Hz}$ までの一部の渦しか表していないと言える。 さらに中心周波数は $875 \mathrm{~Hz}$ まで増加すると、周期性の 小渦列は $y / d=1$ の位置に現す。この位置は各スケール渦 の平均中心軸または大スケールの鞍部点の位置と一致し ている。高周波数 $1750 \mathrm{~Hz}$ では、図 $3(\mathrm{e})$ に示すように、 小さい渦列は $y / d=1$ の位置に現寸が、周期性は弱くなっ ていることがわかる。

図 3 に見られる各スケール渦の空間と時間の分布は大 渦中に中渦が含まれ、中渦はさらに小渦を含む乱流の力 スケード現象を鮮明に示している。この現象を通常の手 


\section{4. 結論}

本研究では、ベクトルウェーブレット多重解像度法を 用いて実験の変動速度ベクトルを周波数空間に分解した。 解析結果に基づいてカルマン渦列中に周期性をもつ様々 なスケール渦が含まれることが定量的に可視化され、後 流乱流の渦構造に関する時間、空間及び周波数の情報を 同時に捕らえた。実験データから乱流のカスケート現象 も再現された。ベクトル多重解像度の結果に基づいて流 線と渦度の表示は、流れ場全体の情報（時間、空間、周 波数、速度、渦の分布及び渦の強さ）を一度に把握する ために非常に有効な可視化手法である。今後、乱流の複 雑な構造の解明を進めることが期待できる。

\section{参 考 文 献}

1) Zhou, Y. and Antonia, R.A.: A Study of Turbulent Vortices in the Wake of a Cylinder, Journal of Fluid Mechanics, Vol.253 (1993), pp.643-661.

2) Li, H.: Identification of Coherent Structure in Turbulent Shear Flow with Wavelet Correlation Analysis, ASME Journal of Fluids Engineering, Vol.120 (1998), pp.778785.

3) Li, H., Takei, M., Ochi, M., Saito, Y. and Horii, K.: Eduction of Unsteady Structure in a Turbulent Jet by using of Continuous and Discrete Wavelet Transforms, Transactions of the Japan Society for Aeronautical and Space Sciences, Vol.42 (2000), pp.190-195.

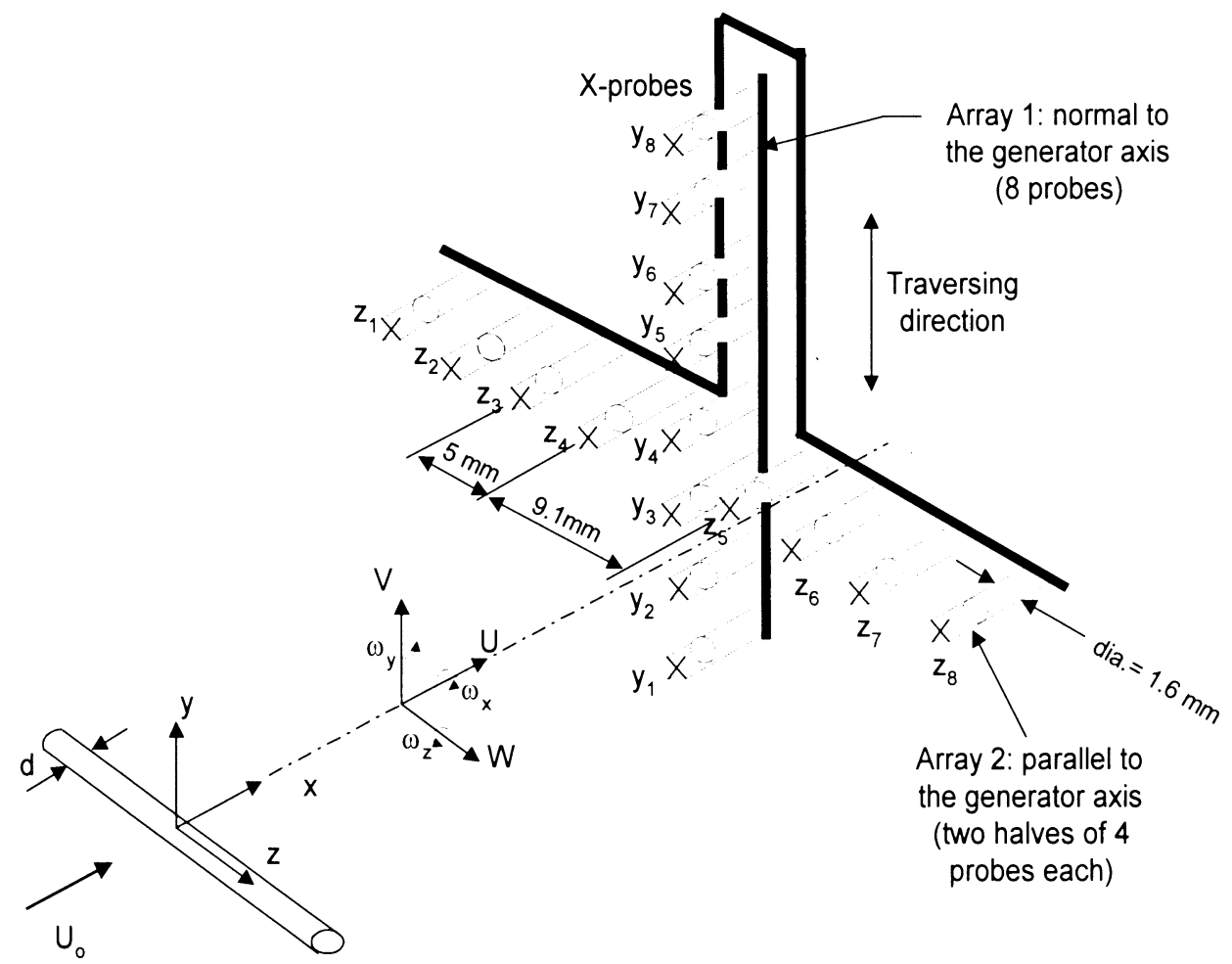

Fig.1 Experimental arrangement 


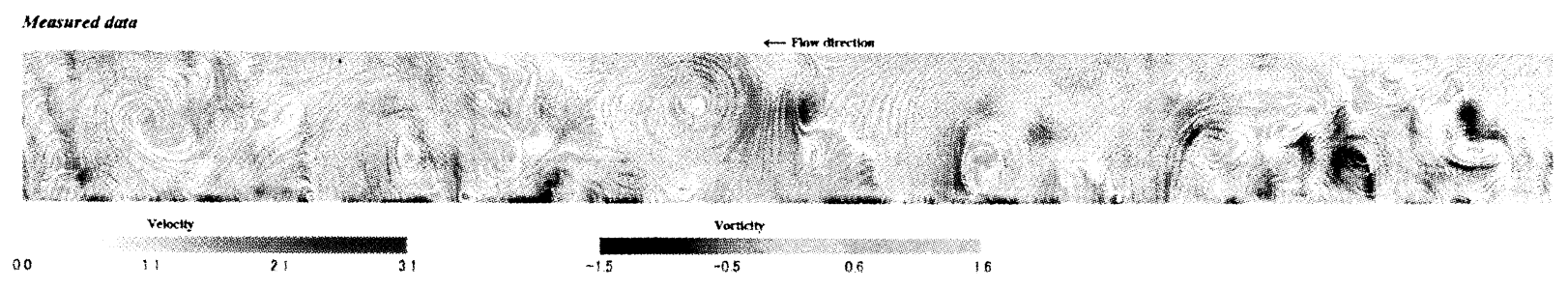

Fig.2 Streamline and vorticity in the $(x, y)$-plane at $x / d=20$
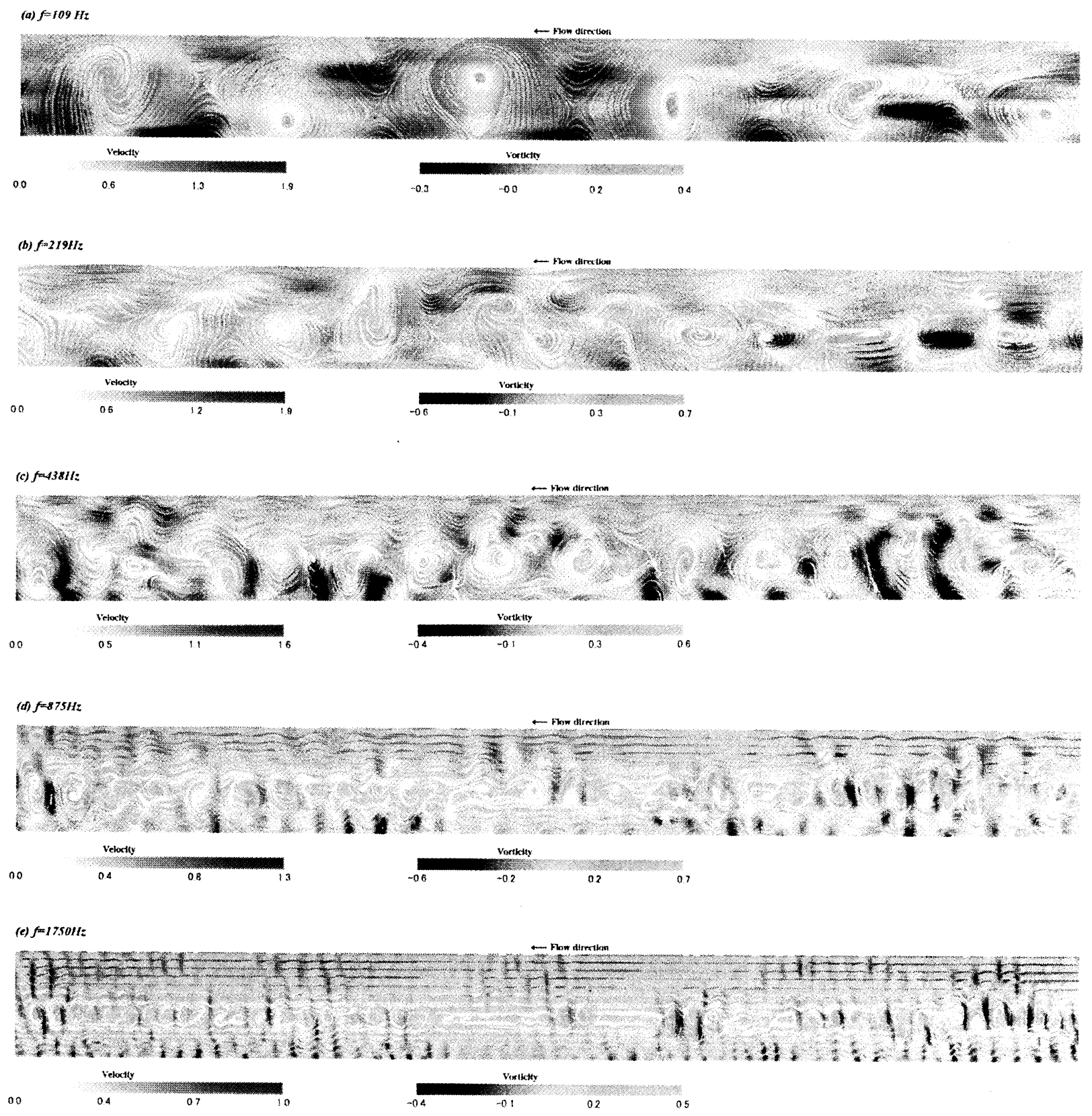

Fig.3 Multiresolution of streamline and vorticity in the (x, y)-plane at $x / d=20$ 